\title{
A METHOD FOR CORRECTING THE ERYTHROCYTE SEDI- MENTATION RATE FOR VARIATIONS IN THE CELL VOLUME PERCENTAGE OF BLOOD ${ }^{1}$
}

\author{
By M. DOROTHY ROURKE AND A. CARLTON ERNSTENE
}

(From the Thorndike Memorial Laboratory, Boston City Hospital; the Medical Research Laboratories, Beth Israel Hospital; and the Department of Medicine, Harvard Medical School, Boston)

(Received for publication December 2, 1929)

Knowledge of the rate of sedimentation of the red blood corpuscles is now generally considered a valuable aid in determining the presence or absence of infection or of tissue damage in the body. ${ }^{2}$ The test is also of prognostic value and can serve as an index of the relative severity of infection and tissue damage.

Obviously the value of the test rests on the assumption that the only factors which affect the rate of settling are directly dependent on the severity of infection or tissue damage. Rourke and Plass (1) have shown that, to obtain a reliable measurement of sedimentation rate, heparin should be used as the anticoagulant, venous stasis should be avoided in collecting the blood, the test should be completed on the day the blood is drawn, and the room temperature during the measurement should remain between $20^{\circ}$ and $25^{\circ} \mathrm{C}$. These investigators also demonstrated that, all other factors being equal, the rate of settling bears an inverse proportion to the volume percentage of red blood cells; the fewer the red blood cells in a given specimen, the faster the sedimentation rate. If heparinized normal blood is prepared so that the cell volume is only 30 per cent, the sedimentation rate will be as rapid as that of blood from a patient with pronounced infection but with no anemia. The influence of variation in cell volume percentage

1 This study was aided by a grant from the DeLamar Mobile Research Fund of Harvard University.

2 Pregnancy is the only physiological process known to be associated with a definite increase in sedimentation rate. 
on the sedimentation rate has been pointed out also by other investigators $(2,3,4,5)$.

Since both anemia and infection accelerate the rate of sedimentation, a correction must be made for the influence of anemia before the test can be used as an accurate index of the severity of infection. Plass and Rourke (6), therefore, advised that a hematocrit determination be made coincident with the measurement of the sedimentation rate and that the rate be expressed as the percentage of total possible settling,

$$
\frac{\mathrm{mm} . \text { clear plasma after } 1 \text { hour settling } \times 100}{\mathrm{~mm} . \text { clear plasma after centrifuging }}
$$

Although this formula corrects roughly for variation in cell volume percentage, the results are too inaccurate to give an exact index of the intensity of infection. The need of a more accurate method for correcting sedimentation rate for variations in cell volume percentage recently became apparent in a study of the rate in rheumatic fever (7). The rate is increased in this disease both by the infection and by the coexistent anemia, and in order to estimate the severity of the infection, an accurate correction for the influence of the anemia must first be made. The same difficulty in interpreting the sedimentation rate occurs in all infections with anemia. Gram (5) realized this difficulty and, using Westergren's method (8), constructed a chart by means of which an approximate correction could be made for variations in cell volume percentage. In constructing this chart he used the results obtained on 18 specimens of blood from 18 patients. He altered the cell volume percentage of each specimen to obtain samples with hematocrit readings between 26 and 50 volumes per cent, and recorded the amount of settling in one hour. The sedimentation rates were then plotted against the cell volume percentages.

Inasmuch as Rourke and Plass (1) have demonstrated that the citrate dilution in the Westergren method introduces uncontrollable variables which prohibit standardized measurement of the sedimentation rate, it is believed that the results obtained by this method do not give as accurate a measure of the amount of tissue damage as is desirable, even when a correction for cell volume is made from Gram's chart. We therefore have measured the sedimentation rate of red blood cells in heparinized plasma and have constructed a chart by 
means of which the rate can be corrected for variations in the cell volume percentage.

\section{METHOD}

It was originally planned to prepare samples of different cell volume percentages from a given specimen of blood in the manner described below, to find the amount of settling in one hour on each sample by the Plass-Rourke method (1), and from the data to construct a reference chart. The curves which resulted from plotting the one hour readings against the corresponding hematocrit readings, however, were not comparable. The variability of these curves evidently was due to the fact that, in pathological blood, the amount of settling in one hour is influenced greatly by the "packing" of the cells during the latter part of the period. The fact that regular curves were obtained with normal blood specimens in which "packing" did not occur is in accord with this interpretation. ${ }^{3}$ The variable degree of packing which occurred in the pathological blood specimens rendered the construction of a standard chart on the basis of one hour readings impossible.

If the amount of settling of the red blood cells is noted at frequent time intervals, a curve can be constructed by plotting the amount of settling against the time. Such a curve has three distinct parts (fig. 2), namely, the period of "aggregation" (section $A$ ), the straight line period of constant sedimentation (section $B$ ), and the period of "packing" (section $C$ ). Fähraeus (9) says of the straight line portion (B) of the sedimentation curve, "It is clear that the sinking velocity which corresponds to the size of the completed aggregates is really only to be found during the intermediate phase of the sedimentation." Furthermore, Lundgren (10) says, "The characteristic feature in the sedimentation curve is the constant falling speed which must stand in a certain quantitative relation to the factor determining the sedimentation, and thus also the size of the aggregates." At the suggestion of Prof. Edwin B. Wilson, we have measured the rate of sedimentation during the period of most rapid settling. The rate during this period is not

${ }^{3}$ Since the tubes used here were only $100 \mathrm{~mm}$. in length and since there was no dilution of cells by citrate solution, packing occurred earlier than in the Westergren method. 
influenced by the period of "aggregation" or the period of "packing." Specimens of blood were manipulated as described below to give samples of different cell volume percentages, and the rate of sedimentation of each sample during the period of constant settling was measured. When these values were plotted against the hematocrit readings, systematic curves of the type seen in figure 4 were obtained.

\section{Method of obtaining data for constructing the reference chart}

1. The sedimentation tubes as described by Plass and Rourke (1) were used. ${ }^{4}$

2. Observing the proper precautions (1), 20 to $30 \mathrm{cc}$. of venous blood were drawn from a patient and added to a test tube containing 10 to $15 \mathrm{mgm}$. of heparin. ${ }^{5}$

3. A part of the specimen was transferred to a sedimentation tube and centrifuged for 30 minutes at 3000 r.p.m. to obtain the cell volume percentage.

4. Six to 9 samples of $3 \mathrm{cc}$. each were then transferred to $15 \mathrm{cc}$. centrifuge tubes and stoppered.

5. The sedimentation rate of one uncentrifuged specimen was measured while all other samples were centrifuged at approximately 700 r.p.m. for 5 minutes.

6. One centrifuged sample was remixed and not changed otherwise. The rate of settling of this sample was measured as described below and compared with the rate of the original uncentrifuged sample.

7. The previously measured hematocrit reading was utilized in calculating the volume of plasma or cells to be removed from the other $3 \mathrm{cc}$. centrifuged samples in order to obtain specimens with cell volume percentages varying from 20 or 25 to 55 per cent of cells. These amounts were removed.

8. Each sample was mixed by tipping it up and down in the stoppered centrifuge tube for at least $2 \frac{1}{2}$ minutes. The sedimentation tube

The tubes have a capacity of 1.20 to $1.25 \mathrm{cc}$. in $100 \mathrm{~mm}$. of length instead of the 1.11 to $1.18 \mathrm{cc}$. as used previously (1).

' One hundred fifty milligrams of heparin were dissolved in $1 \mathrm{cc}$. of distilled water. A capillary pipette was drawn out to deliver approximately 75 drops to 1 cc. One drop ( $2 \mathrm{mgm}$. heparin) of this solution is used for $3 \mathrm{cc}$. of blood and 6 drops (12 mgm. heparin) for 20 to $30 \mathrm{cc}$. of blood. 
was filled to the zero mark and was placed absolutely vertical in a rack. The time was recorded. The room temperature was maintained between $20^{\circ}$ and $25^{\circ} \mathrm{C}$. during the measurement.

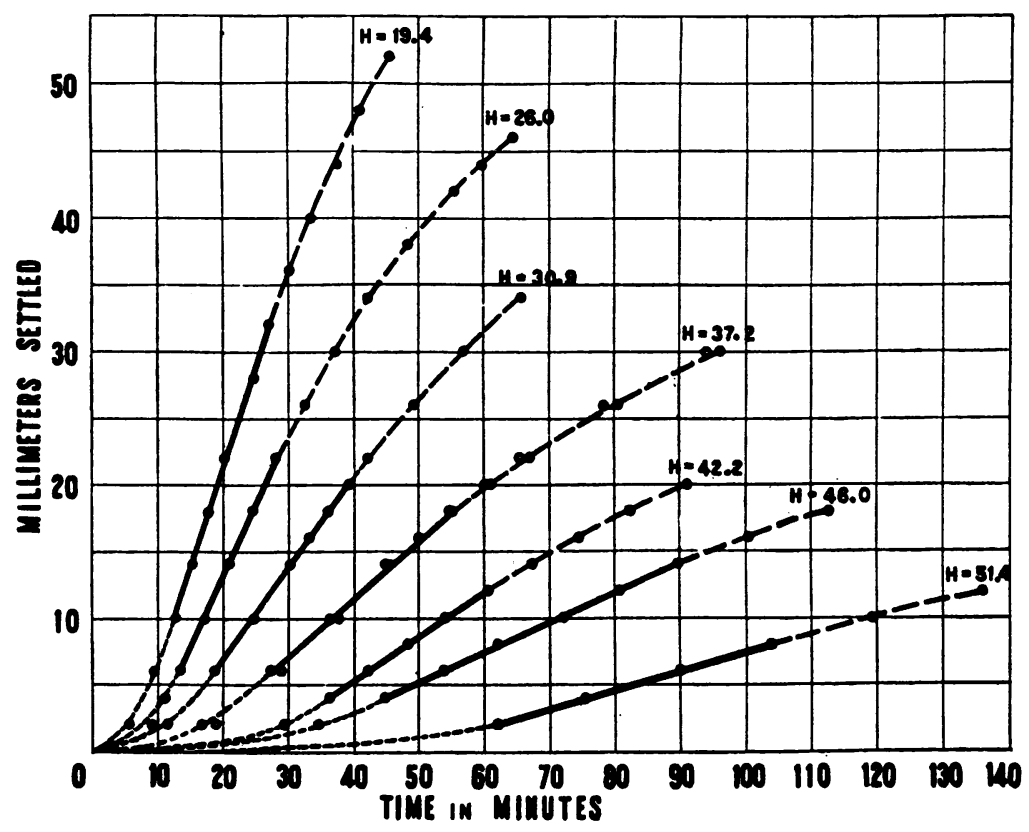

Fig. 1. The Effect of Changes in Cell Volume Percentage on the SediMENTation Rate of a Normal BloOd SPEcimen

All the curves shown were constructed from manipulation of one large blood specimen in such a manner as to give samples of different cell volume percentages as indicated by $\boldsymbol{H}$. Each dot on the curves represents a time-distance reading. The open dots of the curve $B=37.2$ represent readings taken during the settling of the original uncentrifuged specimen, and the solid dots represent readings on an identical sample which had been centrifuged at 700 r.p.m. for 5 minutes and then well mixed before being placed in the sedimentation tube. The heavy solid line on each curve indicates the "straight line" portion of the curve, i.e., the period of most rapid constant settling.

9. The elapsed time and the distance settled were recorded at frequent intervals, until the rate began to diminish because of "packing."

10. All specimens were then centrifuged for 30 minutes at a speed of 3000 r.p.m., and the hematocrit measurements were recorded accurately. 
11. The time-distance readings for each sample were plotted and the curves were drawn as in figure 1. The slopes during the fastest straight line portions of the curves were calculated (fig. 2).

12. These slopes were then plotted against the hematocrit readings (fig. 3).

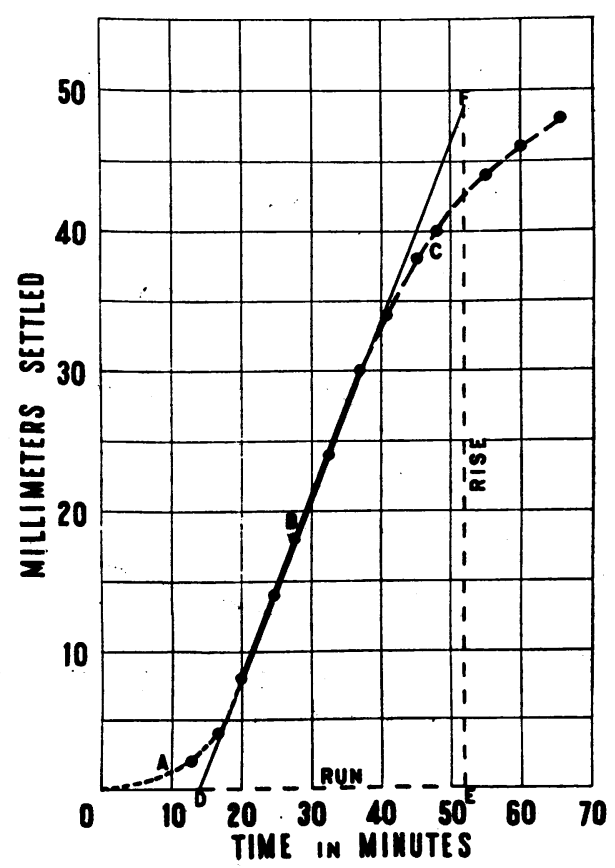

Fig. 2. Calculation of Slope of Straight line Part of Curve

Line $D F$ is the extended straight line portion of the sedimentation curve $A C$. $F E$ is the rise and $D E$ the run of the straight line $D F$. The slope of the straight line part of the curve $=\frac{F E}{D E}$ millimeters per minute.

13. Curves obtained in this manner on 47 blood specimens from 42 patients (9 normal individuals and 33 subjects with various diseases) were assembled in a composite chart (fig. 4).

14. Figure 5 was compiled by taking averages of the curves of figure 4 in such a manner as to give a well spaced reference chart. By means of figure 5 any sedimentation rate at any cell volume per- 
centage can be transposed to the corrected rate at 45 volumes per cent of cells. We have termed this corrected rate the "corrected sedimentation index." The normal limits of the "corrected sedimentation index" have been indicated in figure 5 .

After the blood was transferred to the sedimentation tube, readings of the time and distance of settling were recorded at such intervals that about 4 points could be used for constructing the straight line portion of the curve (section $B$, fig. 2). A little experience with bloods settling at different rates makes it evident at what times observations should be taken. In general, time-distance readings in normal bloods should be made for every $2 \mathrm{~mm}$. of settling. In more rapidly settling specimens, readings should be taken every 4 to $8 \mathrm{~mm}$., until two consecutive readings indicate the onset of "packing." For the construction of the curves of figure 1 , readings were taken more frequently in order to demonstrate the degree of conformity of single readings.

The slope of the straight line portion of the curve is computed as follows. The determined straight line (section $B$, fig. 2) is extended below to the base line of the chart at point $D$ and upwards to any convenient point $F$. A perpendicular $F E$ is dropped from point $F$ to the base line at point $E$. The slope of the line is then obviously $\frac{\text { Rise }}{\text { Run' }}$ $\frac{F E}{D E}=$ millimeters per minute. In the example (fig. 2), therefore, the rate is $\frac{49}{34}$, or $1.44 \mathrm{~mm}$. per minute.

\section{Method of obtaining "corrected sedimentation index" for any blood}

The following method is utilized to obtain the "corrected sedimentation index." Tubes are used similar to those described by Plass and Rourke (1) with a capacity of 1.20 to $1.25 \mathrm{cc}$., a height of $100 \mathrm{~mm}$., and graduated in $2 \mathrm{~mm}$. divisions from 0 at the top to 100 at the bottom. Two or $3 \mathrm{cc}$. of blood are drawn without venous stasis into a dry syringe and transferred immediately to a tube containing $2 \mathrm{mgm}$. of heparin. (See previous description of heparin solution.) The blood is allowed to stand at least 15 minutes to come to the temperature at which the determination is made, $20^{\circ}$ to $25^{\circ} \mathrm{C}$. It should not stand more than 3 hours. The specimen is then mixed by tipping up and down for 2 to 
3 minutes. The sedimentation tube is filled to the zero mark and the degree of settling is recorded at frequent intervals until two readings indicate a decreased rate because of "packing." The sedimentation tube is transferred to a centrifuge and spun at 3000 r.p.m. for $30 \mathrm{~min}$ utes. The slope of the straight line portion of the sedimentation curve is calculated as described above. This value is plotted against the hematocrit value on figure 5. The curve on which this point lies, or if the point comes between curves, the interpolated curve is followed

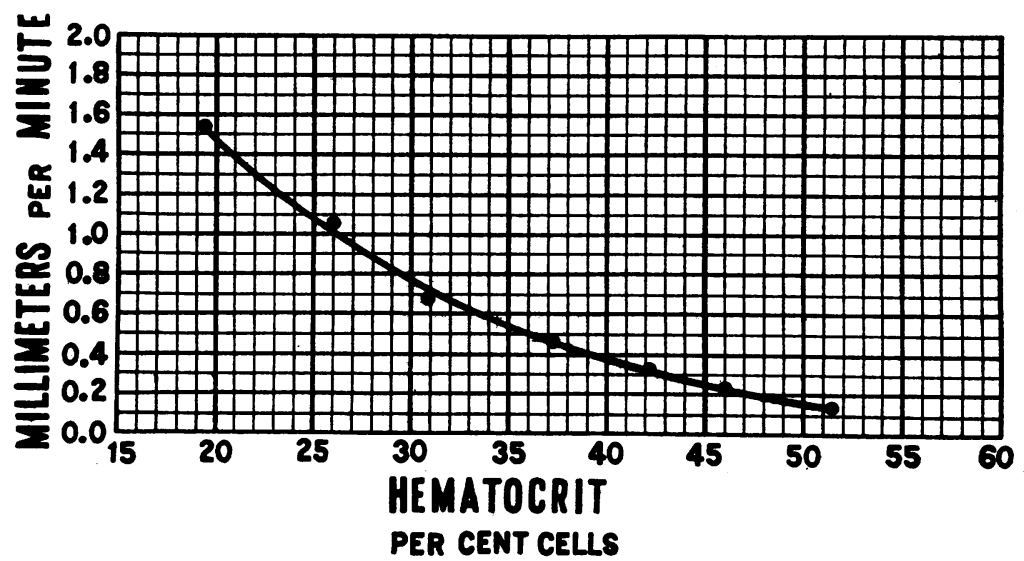

Fig. 3. Relation of the Sedimentation Rate during the Faștest, Constant Faliing Period of Sedimentation to the Hematocrit Value

The dots were obtained by plotting the slope, expressed in millimeters per minute, of the straight line portion of the curves of figure 1 , against the respective hematocrit values. The curve was then drawn from the charted points.

up or down to the hematocrit line of 45 volumes per cent, and the "corrected sedimentation index" recorded.

For example, the slope for the sedimentation rate of the red blood cells of a patient convalescing from rheumatic fever was $0.50 \mathrm{~mm}$. per minute and the hematocrit reading 37.5 volumes per cent of cells. By reference to figure 5, the "corrected sedimentation index" was found to be $0.27 \mathrm{~mm}$. per minute. This value is well within the normal limits, whereas the uncorrected value might well have been interpreted as indicative of persisting infection.

The sedimentation rates on bloods from 6 or 8 patients can readily 
be measured at one time by one observer and the task completed in $1 \frac{1}{2}$ to 2 hours. In the case of bloods from patients with extensive infec-

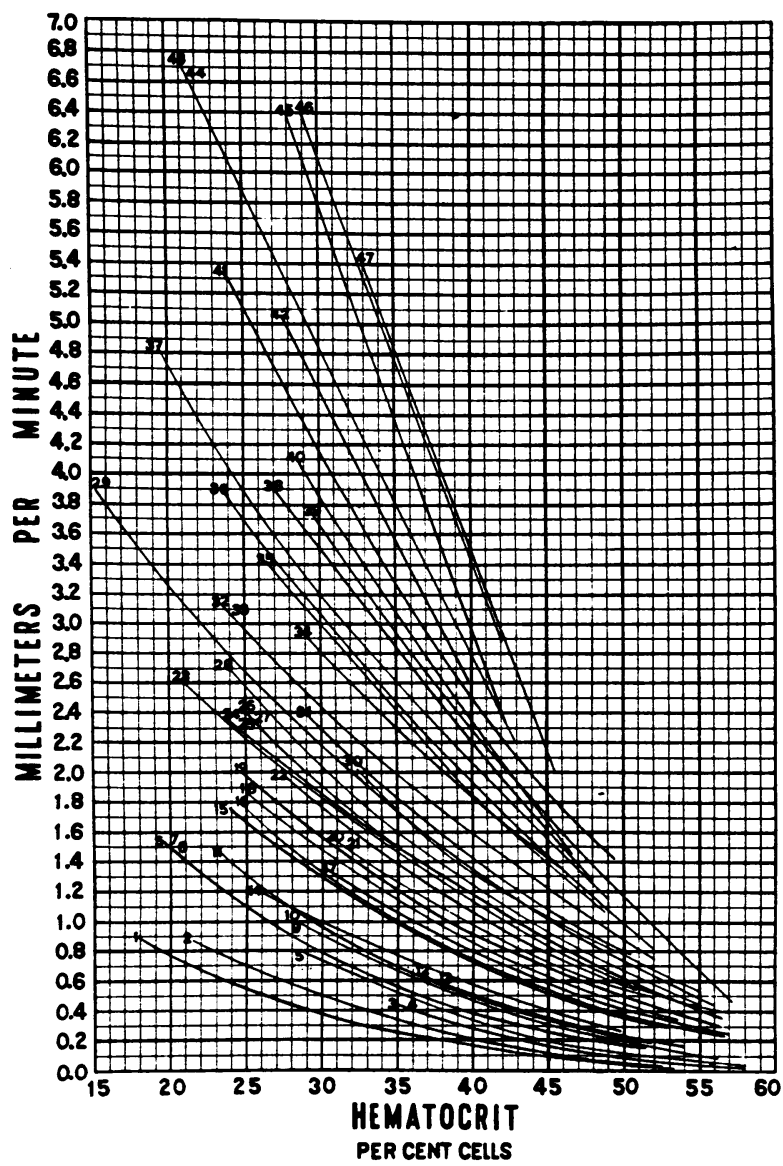

Fig. 4. Composite Chart Showing the Dependence of Sedimentation Rate during the Period of Fastest Constant Settuing on the HEMATOCRIT VALUE

Each curve has been drawn from points plotted as in figure 3. The curves, number 1 to 47, represent results obtained from bloods of patients with diagnoses as indicated by the corresponding numbers of table 1 .

tion, the rate measurement not infrequently is finished in 20 to 30 minutes from the time the sedimentation tube is filled. 
TABLE 1

Sex, diagnosis and blood cell volume of subjects

\begin{tabular}{|c|c|c|c|c|c|}
\hline Number & Name & Sex & $\begin{array}{c}\text { Cell } \\
\text { volume }\end{array}$ & Diagnosis & Remarks \\
\hline & & & per cent & & \\
\hline 1 & B. M. & $\mathbf{M}$. & 45.8 & Normal & \\
\hline 2 & D. S. & M. & 35.2 & Hodgkin's disease & See number 6 \\
\hline 3 & A. E. & M. & 48.3 & Normal & \\
\hline 4 & D. G. & F. & 44.4 & Normal & \\
\hline 5 & E. G. & M. & 50.1 & Normal & \\
\hline 6 & D. S. & $\mathbf{M}$. & 37.0 & Hodgkin's disease & $\begin{array}{l}\text { After x-ray therapy. See } \\
\text { number } 2\end{array}$ \\
\hline 7 & H. N. & M. & 37.5 & $\begin{array}{l}\text { Convalescent rheumatic } \\
\text { fever }\end{array}$ & . \\
\hline 8 & R. B. & F. & 44.5 & Normal & \\
\hline 9 & J. H. & M. & 44.1 & Normal & \\
\hline 10 & J. K. & M. & 40.0 & Convalescent serum sickness & See number 17 \\
\hline 11 & M. D. & F. & 45.0 & Normal & \\
\hline 12 & J. M. & M. & 46.5 & Normal & \\
\hline 13 & S. G. & M. & 46.0 & Normal & \\
\hline 14 & J. R. & M. & 37.8 & Acute maxillary sinusitis & \\
\hline 15 & L. C. & F. & 38.0 & Pulmonary tuberculosis & \\
\hline 16 & B. B. & F. & 39.6 & Bronchopneumonia & \\
\hline 17 & J. K. & M. & 44.3 & Serum sickness & See number 10 \\
\hline 18 & H. T. & M. & 48.0 & Influenza & \\
\hline 19 & C. W. & M. & 44.4 & Lobar pneumonia & \\
\hline 20 & L. $R$. & M. & 40.0 & $\begin{array}{l}\text { Chronic cholecystitis; papil- } \\
\text { loma of bladder }\end{array}$ & \\
\hline 21 & B. G. & M. & 44.4 & Multiple sclerosis & \\
\hline 22 & W. M. & M. & 40.5 & Hodgkin's disease & After x-ray therapy \\
\hline 23 & H. H. & M. & 42.3 & Acute toxic hepatitis & \\
\hline 24 & J. C. & M. & 49.8 & Lobar pneumonia & \\
\hline 25 & F. T. & M. & 37.8 & Portal cirrhosis & \\
\hline 26 & F. K. & M. & 45.5 & Lobar pneumonia & \\
\hline 27 & H. G. & M. & 43.7 & Multiple sclerosis & \\
\hline 28 & P. S. & M. & 41.8 & Gonorrheal arthritis & \\
\hline 29 & D. L. & M. & 44.0 & Influenza & \\
\hline 30 & T. K. & F. & 46.5 & Bronchopneumonia & \\
\hline 31 & M. L. & M. & 48.3 & $\begin{array}{r}\text { Postoperative herniotomy; } \\
\text { streptococcus sore throat }\end{array}$ & \\
\hline 32 & R. J. & $\mathbf{M}$. & 43.5 & Lobar pneumonia & $\begin{array}{l}\text { Convalescent. See num- } \\
\text { ber } 34\end{array}$ \\
\hline 33 & O. 0. & M. & 40.4 & Acute rheumatic fever & \\
\hline 34 & R. J. & M. & 42.0 & Lobar pneumonia & See number 32 \\
\hline 35 & S. P. & M. & 37.6 & Pulmonary tuberculosis & \\
\hline 36 & T. P. & M. & 37.8 & Coronary thrombosis & \\
\hline
\end{tabular}


TABLE 1-Concluded

\begin{tabular}{|c|c|c|c|c|c|}
\hline Number & Name & Sex & $\begin{array}{c}\text { Cell } \\
\text { volume }\end{array}$ & Diagnosis & Remarks \\
\hline & & & per cent & & \\
\hline 37 & H. B. - & M. & 44.6 & Postoperative herniotomy & \\
\hline 38 & C. $\mathrm{H}$. & M. & 39.0 & Acute rheumatic fever & \\
\hline 39 & H. S. & M. & 38.4 & Acute toxic hepatitis & \\
\hline 40 & F. M. & F. & 39.9 & Acute rheumatic fever & \\
\hline 41 & B. S. & M. & 41.1 & Osteosarcoma of ilium & After $x$-ray therapy \\
\hline 42 & S. $\mathbf{K}$. & F. & 37.8 & Acute rheumatic fever & \\
\hline 43 & F. C. & F. & 35.0 & Lobar pneumonia & \\
\hline 44 & O. $R$. & M. & 40.2 & Infectious arthritis & See numbers 45 and 47 \\
\hline 45 & O. R. & M. & 38.2 & Infectious arthritis & See numbers 44 and 47 \\
\hline 46 & H. F. & M. & 41.3 & Lobar pneumonia & \\
\hline 47 & O. R. & M. & 38.3 & Infectious arthritis & See numbers 44 and 45 \\
\hline
\end{tabular}

\section{DISCUSSION}

Forty-seven individual blood specimens from cases of 17 different diseases are represented by complete slope-cell volume percentage curves in figure 4 . Whenever 2 experimental curves were so closely superimposed that it was impossible to present both graphically on the same chart, one curve is numbered twice. For instance, curve numbered 26 and 27 is representative of 2 entirely different diseases, lobar pneumonia and multiple sclerosis; curve numbered 43 and 44 was obtained from the blood of 2 patients, one with lobar pneumonia and the other with active infectious arthritis. The uniformity in the contour of the curves indicates that they all obey the same laws of sedimentation. In other words, the change in rate resulting from variation of the cell volume percentage is not specific for different diseases and, so far as is known, any rate in any disease would vary with change in cell volume percentage in the same manner as is represented by the curves in figure 4. The sex of the patient, hematocrit value of the blood as taken, and the diagnosis are given in table 1.

It may be noted that the curves in figure 4 which represent the results for the 6 most rapidly settling specimens are not extended to hematocrit values above 40 to 45 volumes per cent. The reason for this is that. the curves representing rates at the higher hematocrit readings would have crossed other curves representing slower rates at about 45 volumes per cent. The explanation probably rests on 
the physical nature of the sedimentation process. It may be said, however, that in 2 years experience with the test in many diseases we have never observed a blood to have a hematocrit reading above 45 volumes per cent if the patient had an infection so severe that the rate came within this group. If, however, one should encounter a patient suspected of having extensive infection who shows a hematocrit reading of 45 volumes per cent or greater and a "corrected sedimentation index" indicating relatively little infection, the measurement should be repeated on a sample from which sufficient cells have been removed to give a cell volume percentage between 35 and 40 .

Normal limits of "corrected sedimentation index," 0.08 to $0.35 \mathrm{~mm}$. per minute, have been chosen from the results of 92 measurements on 45 different healthy individuals. The average "corrected sedimentation index" was $0.214 \mathrm{~mm}$. per minute. Of the 92 determinations only 1 result was below 0.08 and only 2 results were above $0.35 \mathrm{~mm}$. per minute. It is generally accepted that the uncorrected sedimentation rate for normal women is faster than for normal men. Bonniger and Herrmann (2) and Gram (11) believe that this difference is due to the lower hematocrit values found for normal women. The results of our observations support this opinion. The average "corrected sedimentation index" of 67 measurements on 31 men was 0.218 ' $\mathrm{mm}$. per minute and for 24 measurements on 14 women $0.203 \mathrm{~mm}$. per minute, a difference which is negligible. Therefore, the same upper and lower limits of normal have been fixed for both sexes. Forty-five volumes per cent of cells has been chosen as the standard hematocrit value, since this value lies about midway between the average cell volume percentage for normal men and normal women.

Fähraeus $(9,12)$ has discussed at length the application of Stoke's Law of settling to the velocity of settling of red blood cell aggregates in plasma. Stoke's Law states that:

$$
V=\frac{2}{9} \frac{g\left(d-d_{1}\right) r^{2}}{\mu}
$$

In this formula $V$ stands for the velocity, $g$ for the acceleration of gravity, $d$ for the density of the settling sphere, $d_{1}$ for the density of the fluid, $\mu$ for the viscosity of the fluid and $r$ for the radius of the settling sphere. It is evident that the velocity of settling would increase greatly 


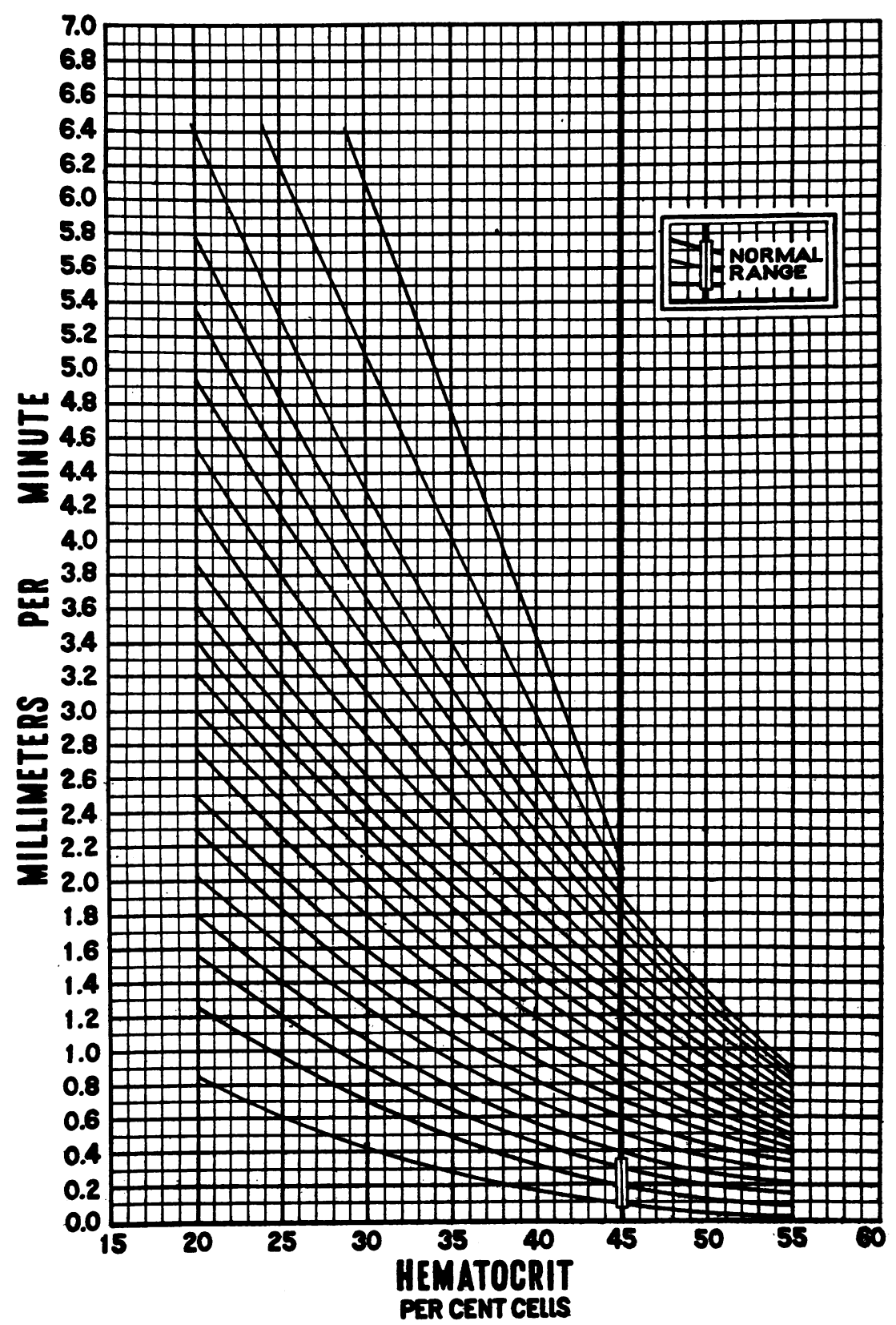

Fig. 5. Reference Chart for Determining "Corrected Sedimentation INDEX"

The millimeters per minute during the period of fastest, constant settling are plotted as abscissae and the hematocrit values as ordinates. The curves of this chart have been obtained by taking averages of the curves in figure 4 at such intervals as to give an evenly spaced chart for easy reference. The reference hematocrit value of 45 volumes per cent of cells has been indicated by the heavy black line. The normal range of "corrected sedimentation index" is shown by the blocked area of the line representing 45 volumes per cent of cells. 
with a comparatively small increase in $r$. Fähraeus studied normal and pathological bloods and found that variations in $d, d_{1}$ and $\mu$ were relatively small compared with variations in $r$, the radius of the red blood cell aggregates. He therefore attributed the more rapid sedimentation of erythrocytes in blood from patients with infection or pregnancy to an increase in the size of the cell aggregates. He showed (12) experimentally that the size of the aggregated clumps of red cells in blood drawn from patients with infection and from women in the last months of pregnancy are larger than those in normal bloods. $\mathrm{He}$ further found (9) the size of the aggregates roughly proportional to the severity of infection.

Stoke's Law applies only to the velocity of settling of a particle in a fluid of infinite extension. It does not take into account the effect of the simultaneous presence of other falling particles in close proximity, the condition met with in the case of sedimentation of the red blood cell aggregates in plasma. Cunningham (13) treats this phase of the problem mathematically and finds that the velocity of the falling particles decreases rapidly as the ratio of the diameter to the distance between particles increases beyond the value of 0.1 . Obviously this factor must be considered before the velocity of settling red blood cell aggregates in plasma can be considered to reflect the size of $r$, the radius of the aggregated clumps of red blood cells, and thus the severity of infection or tissue damage in the body. A practical correction for this variable is made in the case of erythrocyte sedimentation by the use of figure 5 .

\section{SUMMARY AND CONCLUSIONS}

1. The cell volume percentage of a specimen of blood has an important effect on the rate of sedimentation of the red blood cells. The higher the cell volume percentage, the slower the sedimentation rate; and the lower the cell volume percentage, the faster the rate.

2. The value of the sedimentation test as an index of the severity of infection or tissue damage in the body is greatly increased if a correction is made for the effect of variations in cell volume percentage.

3. A chart has been constructed by means of which the rate of sedimentation of any specimen of heparinized blood with a hematocrit reading between 20 and 55 volumes per cent of cells may be transposed 
to the rate which would have obtained had the specimen contained 45 volumes per cent of cells.

4. The "corrected sedimentation index" obtained by the use of this chart is a reliable index of the severity of infection or tissue damage in the body.

5. The normal limits of the "corrected sedimentation index" are from 0.08 to $0.35 \mathrm{~mm}$. per minute.

\section{BIBLIOGRAPHY}

1. Rourke, M.D., and Plass, E.D., J. Clin. Invest., 1929, vii, 365. An Investigation of Various Factors which Affect the Sedimentation Rate of the Red Blood Cells.

2. Bönniger, M., and Herrmann, W., Klin. Wchnschr., 1923, ii, 744. Blutkörperchen-senkungsgeschwindigkeit und -Volumen.

3. Rubin, E. H., and Smith, N. N., Arch. Int. Med., 1927, xxxix, 303. Relation of Hemoglobin, Cell Count, and Cell Volume to the Erythrocyte Sedimentation Reaction.

4. Hubbard, R. S., and Geiger, H. B., J. Lab. and Clin. Med., 1928, xiii, 322. Anemia as a Factor in the Sedimentation Time of Erythrocytes.

5. Gram, H. C., Acta Med. Scandinav., 1928, lxviii, 108. Utber die Correction der Senkungsreaktion für den Einfluss des Zellvolumenprocentes (Haemoglobin) und über die normalen Grenzen der Senkungsreaktion.

6. Plass, E. D., and Rourke, M. D., J. Clin. Invest., 1928, v, 531. A New Procedure for Determining Blood Sedimentation Rates.

7. Ernstene, A. C., Am. J. Med. Sci., In press. Erythrocyte Sedimentation, Plasma Fibrinogen, and Leucocytosis as Indices of Rheumatic Infection.

8. Westergren, A.. Klin. Wchnschr., 1922, i, 1359. UUber die stabilitätsreaktion des Blutes, nebst vergleichwerten bei verschiedener Methodik. Einige Mitteilungen über fortgesetzte Untersuchungen.

9. Fåhraeus, R., Physiol. Rev., 1929, ix, 241. The Suspension Stability of the Blood.

10. Lundgren, R., Acta Med. Scandinav., 1927, lxvii, 63. A Study of the Physical Nature of the Sedimentation of Blood Corpuscles.

11. Gram, H. C., Acta Med. Scandinav., 1929, lxx, 242. The Sedimentation of the Blood-corpuscles in Various Internal Diseases and the Result of Correction of this Value for the Variations of the Hemoglobin Percentage.

12. Fåhraeus, R., Acta Med. Scandinav., 1921, lv, 3. The Suspension-stability of the Blood.

13. Cunningham, E., Proc. Roy. Soc., Sec. A., 1909-10, lxxxiii, 357. On the Velocity of Steady Fall of Spherical Particles through Fluid Medium. 